\title{
Commentary: Bioprosthetic aortic valve replacement: A high standard of comparison for transcatheter aortic valve implantation
}

\author{
Aaron Martin, MD, a,b and Michael H. Yamashita, MDCM, MPH ${ }^{\mathrm{a}, \mathrm{b}}$ \\ From the ${ }^{\mathrm{a}}$ Department of Surgery, Max Rady College of Medicine, University of Manitoba, Winnipeg, Manitoba, \\ Canada; and ${ }^{\mathrm{b}}$ Cardiac Sciences Program, St Boniface Hospital, Winnipeg, Manitoba, Canada. \\ Disclosures: Authors have nothing to disclose with regard to commercial support. \\ Received for publication Oct 27, 2018; accepted for publication Oct 29, 2018; available ahead of print Dec 8, \\ 2018. \\ Address for reprints: Michael H. Yamashita, MDCM, MPH, Y3519 - 369 Tache Ave, St Boniface Hospital, \\ Winnipeg, Manitoba, Canada R2H 2A6 (E-mail: myamashita@ sbgh.mb.ca). \\ J Thorac Cardiovasc Surg 2019;157:2200-1 \\ $0022-5223 / \$ 36.00$ \\ Copyright (c) 2018 by The American Association for Thoracic Surgery \\ https://doi.org/10.1016/j.jtcvs.2018.10.131
}

The contemporary results of bioprosthetic aortic valve replacement (AVR) in elderly patients have become increasingly important as the prevalence of aortic valve disease increases and the application of transcatheter aortic valve implantation widens. The meta-analysis and microsimulation performed by Huygens and colleagues ${ }^{1}$ in this edition of the Journal provides insight into outcomes post bioprosthetic AVR for patients aged 70 years or more. The aim of the study was to assess the early outcomes and project the long-term risks of valve-related events, need for reintervention, and long-term survival for elderly patients undergoing AVR.

Huygens and colleagues ${ }^{1}$ demonstrate that after the initial 2 years postoperatively, the survival post-AVR in elderly patients is comparable to that of the age-matched general population. Thus, AVR places patients back on their expected survival curve after they survive the initial perioperative risks. As well, this study shows that the rates of structural valve degeneration and reintervention are low at $0.42 \% /$ year and $0.56 \% / y e a r$, respectively. These findings support the use of bioprosthetic AVR to treat aortic valve disease in most elderly patients who have a low to intermediate surgical risk profile.

The size of this meta-analysis is impressive, having included 12,842 patients from 40 studies. Furthermore, the methodology is robust, and the authors should be commended for investigating heterogeneity with metaregression, an aspect that is often missing in metaanalyses. The microsimulation also provides potential insight into the projected survival and long-term event rates not otherwise captured.

However, the microsimulation should be viewed with some skepticism because it does not account for all the interactions that occur in reality. For instance, there is a body of literature that outlines with each additional complication the likelihood of mortality increases exponentially. ${ }^{2-4}$ As such, clinicians

\section{References} 2189-97.e14. 2016;102:458-64.

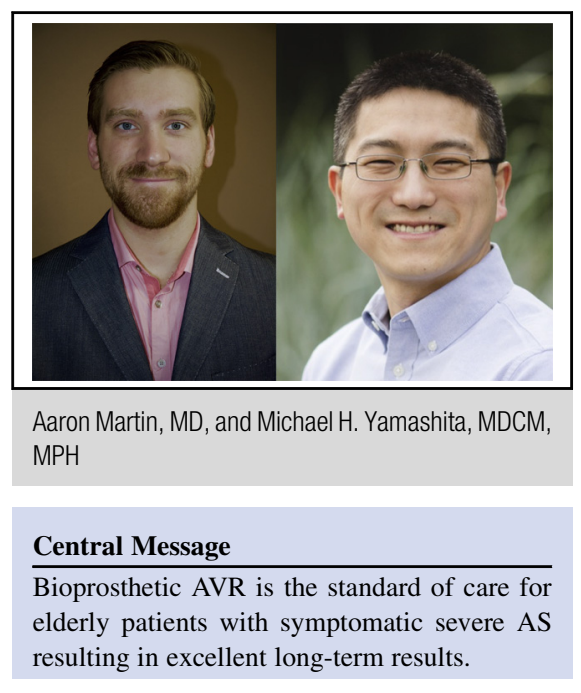

See Article page 2189.

should look at the microsimulation results as more thought provoking than fact. Another weakness of this study was the decision to exclude studies with a minority of patients aged less than 65 years. One such study by Johnston and colleagues ${ }^{5}$ investigated 12,569 patients with a mean age of 71 years. Inclusion of this study would have doubled the number of patients in this meta-analysis and likely would have improved the validity of the results.

AVR continues to be an excellent treatment option for elderly patients with aortic valve disease, and the durability of bioprosthetic valves appears to have a minimal negative impact on elderly patients. This sets a high standard that alternative therapies such as transcatheter aortic valve implantation must match if they are to be more broadly applied to lower-risk patients.

1. Huygens SA, Etnel JRG, Hanif M, Bekkers JA, Bogers AJJC, Rutten-van Moklen MPMH, et al. Bioprosthetic aortic valve replacement in elderly patients: meta-analysis and microsimulation. J Thorac Cardiovasc Surg. 2019;157:

2. Rahmanian PB, Kröner A, Langebartels G, Özel O, Wippermann J, Wahlers T. Impact of major non-cardiac complications on outcome following cardiac surgery procedures: logistic regression analysis in a very recent patient cohort. Interact Cardiovasc Thorac Surg. 2013;17:319-27.

3. Edwards FH, Ferraris VA, Kurlansky PA, Lobdell KW, He X, O'Brien SM, et al. Failure to rescue rates after coronary artery bypass grafting: an analysis from the Society of Thoracic Surgeons adult cardiac surgery database. Ann Thorac Surg. 
4. Crawford TC, Magruder JT, Grimm JC, Suarez-Pierre A, Sciortino CM, Mandal K, et al. Complications after cardiac operations: all are not created equal. Ann Thorac Surg. 2017;103:32-40.
5. Johnston DR, Soltesz EG, Vakil N, Rajeswaran J, Roselli EE, Sabik JF III, et al Long-term durability of bioprosthetic aortic valves: implications from 12,569 implants. Ann Thorac Surg. 2016;99:1239-47. 